\title{
Exploring the satisfaction of surgical patients in the Surgical ER short- \\ stay unit. Correlation of the initial anxiety and pain with the final satisfaction: a quality criterion of nursing
}

Evangeli Charisi ${ }^{1}$, Georgios Tagarakis ${ }^{1}$, Dimitrios Zacharoulis ${ }^{2}$, Nikolaos Tsilimingas ${ }^{1}$

1-Department of Cardiovascular and Thoracic Surgery, University Hospital of Thessaly, Larissa, Greece

2-Department of Surgery, University Hospital of Thessaly, Larissa, Greece

\section{$\underline{\text { Abstract }}$}

Introduction: The main indicator for the evaluation of nursing services is the overall perception of the patients receiving care from the health care unit they visit.

Purpose: Was To investigate the satisfaction of surgical patients hospitalized in SSU-ER-short stay unit (MVN). In addition, to investigate the correlation between the initial anxiety and pain and the severity of final diagnosis.

Materials and methods: The study included a total of 302 consecutive patients hospitalized in the MVN during a period of six months. The satisfaction questionnaire used were the SERVQUAL.I and the "Hospital Anxiety and Depression Scale" (Hospital Anxiety and Depression Scale, HADS). The pain assessment was done by the visual analog scale (VAS).

Results: The study included 198 men aged 49,3 $\pm 25,39$ years and 104 women aged 56,78 $\pm 20,58$ years. The average patient satisfaction was equal to or higher than 6 in the 7-point Likert scale (all dimensions contemplated). The average stress $(7,67 \pm 2,90)$ was higher than the threshold 7 for normal price, while in the case of depression the average findings were within normal limits $(5,00 \pm 2,98)$. Statistically significant differences were observed in the level of overall satisfaction among the various categories of patients $[F(5,296)=4,130, p=0,001)]$. Higher levels of anxiety and pain were positively associated with overall satisfaction $(p<0,01)$.

Conclusion: The level of satisfaction in MVN is important, but requires individualized care and improvement of objective parameters associated with organizational and economic factors.

Keywords: satisfaction; patients; pain; trauma

\section{Council for Innovative Research}

Peer Review Research Publishing System

Journal: Journal of Social Sciences Research

Vol .6, No.3

jssreditor.cir@gmail.com

www.jssronline.com

1083 | P a g e 


\section{ISSN 2321-1091}

\section{INTRODUCTION}

The main indicator for the evaluation of health services is the overall perception of the patients receiving care from the health care unit they visit. The degree of patient satisfaction depends on three factors: (a) patients' expectations of the service, (b) socioeconomic characteristics of patients and (c) psychosocial characteristics. ${ }^{1,2}$ Patient satisfaction depends directly on the extent to which their expectations are verified by the health services and is measured as the difference between what you expect and what you ultimately enjoy.

The patient satisfaction than that given in this care is very important for the health service to hosts, as health professionals who provide care, but also for the patient who subjectively assess their health, according to the standards and expectations of both the conservation and the protection of health. ${ }^{5,6}$

Health services in primary element of patient satisfaction is the result of good health and restoring health. ${ }^{7}$

According to Shipley et al and Rentrop et al, the opinion surveys of patients about the services they receive, is a key indicator of quality of health care, and more accurate than the corresponding criteria and standards relating to the provision of the same services. ${ }^{8,9}$

The measurement of satisfaction of users of health services should be performed at regular intervals in the evaluation and improvement of customer services.10. In our country, the corresponding efforts are few and apospasmatikes. ${ }^{11-15}$ However, recent years have seen increased interest in patient satisfaction from Greek hospitals, in a harsh financial environment and lingering problems in the logistical infrastructure. ${ }^{16,17}$. However, both in Greece and internationally, the studies relating to the MVN is minimal, although the MVN serve large numbers of patients and proper operation can significantly decongest hospitals. After all, MVN, like emergency departments are parts first contact with the patient's medical and nursing satisfaction than those related to the overall satisfaction of the nursing unit, but with the success of the treatment approach of the 18th anxiety and depression, as well as pain should be taken seriously as an integral part of the treatment, as they allow for effective bio-psychosocial approach and better outcome of the disease. The quality of care varies and is determined according to the needs created by the users of the public health system. ${ }^{19 .}$

Knowledge of quality and satisfaction helps to identify the needs and desires of the patient and his approach as a single entity psychosocial, to individualize treatment not only to increase the survival of life and be able to enjoy more health in the years that have a quality of life (quality of life years). ${ }^{20,21 .}$

The purpose of this research was to investigate the satisfaction of surgical patients hospitalized in MVN and correlate with levels of anxiety and pain. The objective was to study these parameters as criteria of quality of nursing services in MVN.

\section{Material and methods}

The study included a total of 302 consecutive patients hospitalized in MVN during a month. The patients were all injured for various reasons, they spoke Greek well and did not suffer from dementia.

The satisfaction questionnaire that was applied was SERVQUAL, modified to refer to hospital infrastructure and personnel of healthcare institutions, with the addition of some questions relating to demographic elements of patients ${ }^{22}$. The five most representative dimensions for the measure of service quality SERVQUAL are in order of importance:

- Reliability (Reliability) - doing what they say they will do, on time and specific.

- The Response (Responsiveness) - the willingness to help and respond to specific requirements

- Security (Assurance) - possession of the requisite skills for the provision of transmission service and confidence.

- Understanding (Empathy) - it shows understanding of customer needs and the provision of the service

- Tangible dimension (Tangibility) Includes physical appearance of people and facilities

Patient satisfaction is a critical indicator of the quality and effectiveness of care. ${ }^{23}$ It connects both nursing care and the organizational environment ${ }^{24}$. Patient satisfaction of care received as a criterion of quality of service, faith services health and health behavior of users across the healthcare system 25,26 .

The evaluation of the incidence of development of mental disorders was performed using the "Hospital Anxiety and Depression Scale" (Hospital Anxiety and Depression Scale, HADS). The HADS scale is a handy tool to investigate the mental status of hospitalized patients. With this scale is estimated the two most common mental disorders that develop in hospitalized patients, anxiety and depression. ${ }^{27} 28$

The scale includes a total of 14 questions, 7 of which relate to the assessment of the development of anxiety and the remaining 7 assessing depression. Each sub-question contains four options which are rated from $0-3$. The overall result obtained for each individual disorder can range from 0-21. As proposed to pathological situations characterized patient questionnaires which assign scores $>11$, while overall result $<7$ is considered as non-pathological. Result 8-10 classified as doubtful case. The HADS scale has been translated into Greek and checked the validity and reliability of a terminally ill cancer patients by Mystakidou et al, 27 in 2004. Also satisfactory reliability and validity of the scale were found by Michopoulos et al, ${ }^{29}$ when the scale was applied to patients pathological and surgical departments.

The pain assessment was done by the visual analog scale (VAS). It is a horizontal scale of length $100 \mathrm{~mm}$, in which 0 corresponds to no pain and 100 at worst. The patient is asked according to his feeling to choose a place which 
corresponds to the intensity of pain. ${ }^{30,31}$

The questionnaires were completed by the patients themselves, under the presence of the researcher. Patients were asked a separate question about their overall satisfaction with medical and nursing services. The responses were calibrated in 5 point scale Likert. Permission for the study was given by the ethics committee of PPGNL.

\section{Statistical analysis}

Descriptive and inferential statistics was performed. Methods used parametric ANOVA and t-test, and correlations by Spearman. The level of statistical significance was set at $p<0.05$. We applied the statistical program SPSS 21.0.

\section{Results}

The study involved 198 men aged 49,3 $\pm 25,39$ years and 104 women aged 56,78 $\pm 20,58$ years. Eighteen subjects (6\%) were uninsured. The distribution of patients by surgical category was as follows: 20 thoracic patients, 44 needed thoracic assessment, 64 surgical patients, 81 neurosurgical patients, 89 surgical patients and 4 ENT patients (Table 1). The average patient satisfaction was equal to or higher than 6 in 7 pointLikert scale in all dimensions contemplated. The average stress $(7,67 \pm 2,90)$ was higher threshold 7 for normal price, while in the case of depression were within normal limits $(5,00 \pm 2,98)$. The assessment of pain VAS scale showed average $66,49 \pm 16,35$ (Table 2). The overall satisfaction with medical and nursing services was high (4,12 $\pm 0,33$ and 4,28 $\pm 0,56$, respectively). Statistically significant differences were observed in the level of overall satisfaction among the various categories of patients $[F(5,296)=4,130, p=0,001)]$. The thoracic patients had a higher level of satisfaction with their neurosurgical $(6,59 \pm 0,25$ vs. $6,29 \pm 0,21, p<0,05)$ and orthopedic patients $(6,27 \pm 0,37, p<0,05$ - graph 1 Higher levels of anxiety and pain were positively associated with overall satisfaction $(p<0,01)$ - table 3 .

\section{Discussion}

The results of this study show that the level of satisfaction with the services provided to the MVN is high. The areas involved in the care of the nursing staff and medical services purely concentrate very high scores. However, patients are concerned about the adequacy of logistics. The satisfaction of this factor varies in a rather modest level. Another characteristical finding is that the intensity of pain was positively correlated with satisfaction, as does the rating scale of anxiety. Highest score on both scales (ie more anxiety and more pain when entering the patient in MVN) were associated with greater satisfaction.

Pain and anxiety of patients have been correlated positively with satisfaction with hospital services and their positive correlation with satisfaction in this study probably indicates successful medical and nursing intervantions ${ }^{.32}$ Given that the average hospitalization did not exceed 10 hours, but that was for surgical cases of varying severity and multiple needs, responses of patients suggests that a high level of provision of medical and nursing services was offered. This is particularly important as the MVN is the first substantial contact with the patient's hospitalization conditions and is expected to affect his view of the general conditions of hospitalization, but also comply with the requirements of hospitalization $^{18 .}$

The problems of infrastructure in hospitals affect patients and healthcare professionals and cancel much of the efforts for the successful treatment of patients. In Greek hospitals this contradiction occurs frequently: Satisfaction with medical and nursing services and dissatisfaction with physical infrastructure, even if it is in higher grade hospitals. This phenomenon is more pronounced in recent years, which perhaps could be attributed to fiscal austerity measures having equivalent effect on the budgets of hospitals. ${ }^{16.17}$

Also, the emergence of different levels of satisfaction depending on the cause turnout of surgical patients demonstrates the importance to be given to the specific needs of each patient and the need for a multifaceted approach. This finding is consistent with relevant international surveys showing that satisfaction with the care provided varies depending on the needs of patients and may diverge considerably, even for objectively similar hospitalization circumstances. ${ }^{22,32,33}$

The fact that patients were from a single hospital and surgical patients only limit the generalizability of the results. But it is indicative of conditions in the Greek MVN and shows the need to improve certain aspects in the care of patients, mainly associated with the provided infrastructure. Future research could identify those patient characteristics that act as predictors of satisfaction in MVN per patient category.

This is the first Greek study that examines satisfaction of the patients during their stay in MVN. The results allow both optimism regarding the work provided by doctors and nurses, but also indicate the need for individualized care and improvement of objective parameters hospitalization associated with organizational and economic factors.

\section{REFERENCES}

1 Moore St, Bopp Kd. How consumers evaluate health care quality: Part I. Health Mark Q 1999, 16: 1-6

2 Papagiannopoulou B Pierakos C, Sarris G, C Yfantopoulos. Measuring satisfaction with health services in a pediatric hospital in Athens. latr2008 Arch Eng, 25: 73-82

3. Miaoulis G Jr, Gutman J, Snow MM. Closing the gap: The patient-physician disconnect. Health Mark Q 2009, 26: 56-68

4. Parasuraman A, Zeithaml VA, Berry LL: A Conceptual Model of Service Quality and Its Implications for Futuring 
Research. Journal of Marketing 1985, 49: 41-50.

5. Ewles, L. \& Simnett, I. (2011). Promoting Health: A Practical

Guide. (Scientific Editor Greek Publication: taste, A.

K.., Barbuda, K.. A.. \& Barber-Kremastinou, Jr.) Athens: Pashalidis SA ..

6. Scriven, A. (2010). (6th ed) Promoting Health: A Practical Guide. Elsevier Ltd

7 I Kotsagiorgi., K Gekas. "Satisfaction of the health care provided." Step Asclepius. 9th Volume, Number 4, OctoberDecember 2010, pp 398-406.

8. Shipley K, Hillborn B, Hansell A, Tyrer J, Tyrer P. Patient satisfaction:

A valid index of quality of care in a psychiatric service. Acta Psychiatr Scand 2000, 101: 330-333

9. Rentrop M, Bohm A, Kissling W. Patient satisfaction with psychiatric care. Historical perspective, methods and results from the international literature. Fortschr Neurol Psychiatr 1999, 67: 456-465

10. Sitzia J, Wood N, Patient satisfaction: A review of issues and concepts. Soc Sci Med 1997, 45: 1829-1843

11.Kyriopoulos C Georgoussi E, A Genimata. Satisfaction of users of health services in public hospitals. In: Kyriopoulos C Georgoussi E. (eds.) Patients and health professionals in Greece. College of Health Professions, Athens, 1994: 11-24

12 Niakas D Gardelis Ch. Inpatient satisfaction in a regional general hospital in Athens. Medical 2000.77: 464-470

13 Souliote K Dolgeras A, Kontos S, Economou Ch. Satisfaction valences of hospital care in Greece: Results of opinion survey in the greater Athens area. Primary Health Care 2002, 14: 114-118

14 C. Dimas, J. Bouras. Multicriteria evaluation of patient satisfaction. Medicine 2007, Vol 92,

15.Pierrakos F, F Tomaras. Patient satisfaction in developing health services Marketing. Nursing 2009, 48: 104-113

16.Niakas D, Gnardellis C, Theodorou M. Is there a problem with quality in the Greek hospital sector? Preliminary results from a patient satisfaction survey. Health Serv Manage Res. 2004; 17 (1): 62-9.

17.Matis GK, Birbilis TA, Chrysou OI. Patient satisfaction questionnaire and quality achievement in hospital care: the case of a Greek public university hospital Health Serv Manage Res November 1, 2009 22: 191-196

18. Kleefstra S, Kool R, Zandbelt L, de Haes J. An instrument assessing patient satisfaction with day care in hospitals.BMC Health Serv Res. 2012 May 24; 12: 125. doi: 10.1186 / 1472-6963-12-125.

19.Sarris M, Goulas A, B Gioka, Soulis S.. Patients' quality of life and quality of care after renal transplantation. Arch Eng Med 2008, 25: 201-208

20.Yfantopoulos G. "Quality of life and survival qualitatively weighted years as measuring parameters of health." Files Greek Medicine, 2001, 18 (92): 114-130.

21.Kontodimopoulos N, Niakas D. "An Estimate of Lifelong Costs and QALYs in Renal Replacement Therapy Based on Patients' Life Expectancy", Health Policy, 2008; 86 (4): 85-96.

22.Szyca R, Rosiek A, Nowakowska U, Leksowski K. Analysis of factors influencing patient satisfaction with hospital treatment at the surgical department. Pol Przegl Chir. 2012; 84 (3): 136-43.

23.Ervin NE. Does patient satisfaction contribute to nursing care quality? J Nurs Adm. 2006; 36 (3): 126-130.

24.Wagner D, Bear M. Patient satisfaction with nursing care: a concept analysis within a nursing framework. J Adv Nurs. 2009; 65 (3): 692-701.

25.Palese A, Tomietto M, Suhonen R, Efstathiou G, Tsangari H, Merkouris A, Jarosova D, Leino-Kilpi H, Patiraki E, Karlou C, Balogh Z, Papastavrou E. Surgical patient satisfaction as an outcome of nurses' caring behaviors: a descriptive and correlational study in six European countries. J Nurs Scholarsh.2011; 43 (4): 341-350.

26.Laschinger HS, Hall LM, Pedersen C, Almost J. A psychometric analysis of the patient satisfaction with nursing care quality questionnaire: an actionable approach to measuring patient satisfaction. J Nurs Care Qual. $2005 ; 20$ (3): $220-230$.

27.Mystakidou K, Tsilika E, Parpa E, Katsouda E, Galanos A, Vlahos L. The Hospital Anxiety and Depression Scale in Greek cancer patients: Psychometric analyses and applicability. Support Care Cancer 2004, 12: 821-825

28.Cameron IM, Crawford JR, Lawton K, Reid IC (2008) Psychometric comparison of PHQ-9 and HADS for measuring depression severity in primary care. Br J Gen Pract 58: 32-36.

29.Michopoulos I. Et.al. Hospital Anxiety and Depression Scale (HADS): validation in a Greek general hospital sample. 2008, Annals of General Psychiatry

30.Dobrogowski J, Mayzner-Zawadzka E, Drobnik L et al. Postoperative pain relieving - recommendations 2008. Ból 2008; 9. 
31.Wołowicka L. Anaesthesiology and intense care - Clinic and nursing. Warszawa 2007.p. 289-296

32.Zyoud SH, Al-Jabi SW, Sweileh WM, Morisky DE. Relationship of treatment satisfaction to medication adherence: findings from a cross-sectional survey among hypertensive patients in Palestine. Health Qual Life Outcomes. $2013 ; 11$ (1): 191

33.Ene KW, Nordberg G, Bergh I, Johansson FG, Sjöström B. Postoperative pain management - the influence of surgical ward nurses. J Clin Nurs. 2008; 17 (15): 2042-50.

Table 1. Demographic characteristics and categorization of patients

\begin{tabular}{|c|c|c|}
\hline & N & $\%$ \\
\hline Sex & & \\
\hline Women & 198 & 65,6 \\
\hline Insurance coverage & 104 & 34,4 \\
\hline YES & 284 & 94,0 \\
\hline NO & 18 & 6,0 \\
\hline Categories surgical patients & & \\
\hline Thorax & 20 & 6,6 \\
\hline For thoracic assessment & 44 & 14,6 \\
\hline Surgical & 64 & 21,2 \\
\hline Neurosurgery & 81 & 26,8 \\
\hline Orthopedics & 89 & 29,5 \\
\hline Otolaryngology & 4 & 1,3 \\
\hline
\end{tabular}

Table 2: Satisfaction and psychological parameters in study patients

\begin{tabular}{|l|l|}
\hline & $\mathrm{MT} \pm \mathrm{TA}$ \\
\hline Pain & \\
\hline VAS & $66,49 \pm 16,35$ \\
\hline Psychological parameters & \\
\hline Anxiety & $7,67 \pm 2,90$ \\
\hline Depression & $5,00 \pm 2,98$ \\
\hline Dimensions of satisfaction & \\
\hline Tangible & $5,99 \pm 0,30$ \\
\hline Reliability & $6,49 \pm 0,46$ \\
\hline Response & $6,50 \pm 0,44$ \\
\hline Safety & $6,44 \pm 0,38$ \\
\hline Empathy & $6,33 \pm 0,34$ \\
\hline & \\
\hline Medical staff & $4,12 \pm 0,33$ \\
\hline
\end{tabular}


Nursing

\begin{tabular}{|l|l|}
\hline & $\mathrm{MT} \pm \mathrm{TA}$ \\
\hline Pain & \\
\hline VAS & $66,49 \pm 16,35$ \\
\hline Psychological parameters & \\
\hline Anxiety & $7,67 \pm 2,90$ \\
\hline Depression & $5,00 \pm 2,98$ \\
\hline Dimensions of satisfaction & \\
\hline Tangible & $5,99 \pm 0,30$ \\
\hline Reliability & $6,49 \pm 0,46$ \\
\hline Response & $6,50 \pm 0,44$ \\
\hline Safety & $6,44 \pm 0,38$ \\
\hline Empathy & $6,33 \pm 0,34$ \\
\hline & \\
\hline
\end{tabular}

Graph 1. Thikogramma satisfaction categories of surgical patients

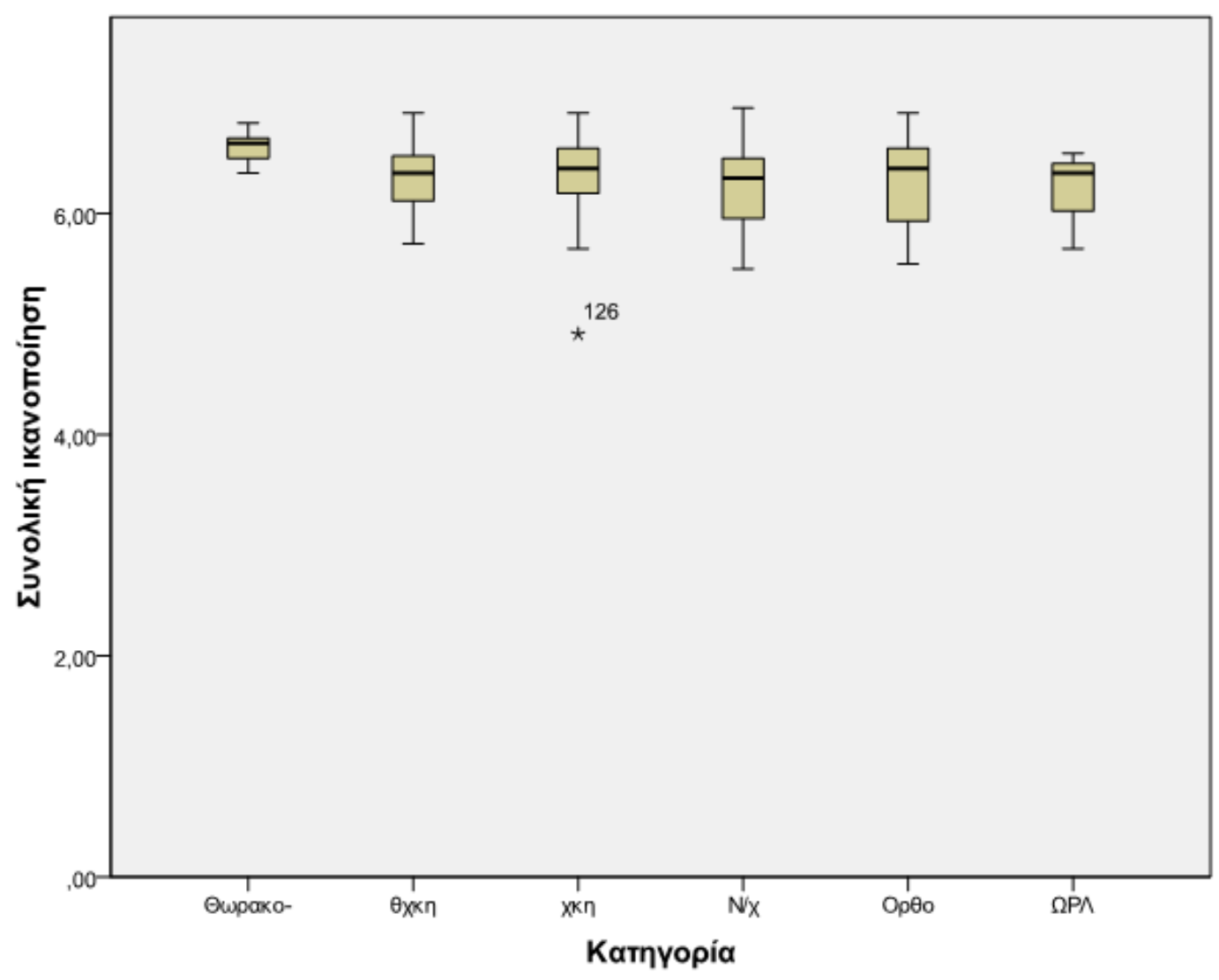


Table 3. Correlations between satisfaction and psychological parameters / pain

\begin{tabular}{|l|l|l|l|l|l|}
\hline $\mathrm{N}=302$ & & & $\mathrm{~A}$ & $\mathrm{D}$ & $\begin{array}{l}\text { VAS } \\
\text { EI }\end{array}$ \\
\hline $\begin{array}{l}\text { Spearman } \\
\text { 's rho }\end{array}$ & $\begin{array}{l}\text { Overall } \\
\text { Satisfaction }\end{array}$ & $\begin{array}{l}\text { Correlation } \\
\text { Coefficient }\end{array}$ &, 162 &, 016 &, 155 \\
\cline { 4 - 7 } & & Sig. (2-tailed) &, 007 &, 791 &, 009 \\
\cline { 3 - 7 } & & & & \\
\hline
\end{tabular}

